3 Garraway WM, Whisnant JP, Drury I. The changing pattern of survival following stroke. Stroke 1983; 14:699-703.

4 Anonymous. Why has stroke mortality declined? [Editorial]. Lancet 1983;i:1195-6.

5 National Board of Health and Welfare. International statistical classification of diseases, injuries and causes of death 1965 revision, adapted for indexing of hospital records and morbidity statistics. $3 \mathrm{rd}$ ed. Stockholm: Liber, 1973

6 Aho K, Harmsen P, Hatano S, Marquardsen J, Smirnov VE, Strasser T. On behalf of the participants in the WHO collaborative study on the control of stroke in the community. Cerebrovascular disease in the community. Results of a WHO collaborative study. Bull W'HO 1980;58:113-30.

7 Ahlbom A. Acute myocardial infarction in Stockholm. A medical information system as an epidemiological tool. Int f Epidemiol 1978;7:271-6.

8 Breslow NE, Day NE. Indirect standardization and multiplicative models for rates, with reference to the age adjustment of cancer incidence and relarive frequency data. $\mathcal{f}$ Chronic Dis $1975 ; 20$ : 239-303.

9 Harmsen, P, Berglund G, Larsson O, Tibblin G, Wilhelmsen L. Stroke registration in Göteborg, Sweden 1970-75. Incidence and fatality rates. Acta. Med Scand 1979;206:337-44.

10 Garraway WM, Whisnant JP, Furlan AJ, Phillips LH, Kurland LT, O'Fallon W'M. The declining incidence of stroke. $N$ Engl f Med 1979;300:449-52

11 Kotila M. Declining incidence and mortality of stroke? Stroke 1984;15:255-9.

12 Robins M, Baum HM. The national survey of stroke. Incidence. Stroke 1981;12(suppl 1):45-57.

13 Mettinger KL, Söderström CE, Allander E. Epidemiology of acute cerebrovascular disease before the age of 55 in Stockholm County 1973-77. I. Incidence and mortality rates. Stroke 1984;15:795-801

14 Terént A. Acute cerebrovascular diseases. Uppsala: University Hospital, 1980. (Thesis.

15 von Arbin M, Britton M, de Faire U, Helmers C, Miah K, Murray V. A study of stroke patients treated in a non-intensive stroke unit or in general medical wards. Acta Med Scand 1980;208: $81-5$
16 Strand T, Asplund K, Eriksson S, Hägg E, Lithner F, Wester PO. A non-intensive stroke unit reduces functional disability and the need for long-term hospitalization. Stroke 1985;16:29-38. 17 Cooper SW, Olivet JA, Wollsey FM Jr. Establishment and operation of combined intensive care unit for patients with cardiac and cerebrovascular disease. NY State $\mathcal{F}$ Med 1972;72:2215.

18 Drake WE Jr, Hamilton MJ, Carlsson M, Blumenkrantz J. Acute stroke management and patient outcome, the value of neurovascular care units (NCU). Stroke 1974;4:933.

19 Hewer RL. Stroke units. Br.Med 7 1972;i:52.

20 Veterans Administration Cooperative Study Group on Antihypertensive Agents. Effects of treatment on morbidity in hypertension: results in patients with diastolic blood pressure averaging 115 through $129 \mathrm{~mm} \mathrm{Hg}$. IAMA 1967;202:1028-34.

21 Veterans Administration Cooperative Study Group on Antihypertensive Agents. Effects of treatment on morbidity in hypertension. II. Results in patients with diastolic blood pressure averaging 90 through $114 \mathrm{~mm} \mathrm{Hg}$. JAMA 1970;213:1143-52.

22 Helgeland $\mathrm{A}$. Treatment of mild hypertension, a five year controlled drug trial: the Oslo study. $A m$ f Med 1980;69:725-32.

23 Report by the Management Committee. The Australian therapeutic trial in mild hypertension. Lancel $1980 ; \mathrm{i}: 1261-7$

24 Hypertension Detection and Follow Up Program Cooperative Group. Five-year findings of the hypertension detection and follow-up program. III. Reduction in stroke incidence among persons with high blood pressure. FAMA 1982;247:633-8.

25 Black DG, Heagerty AM, Bing RF, Thurston $\mathrm{H}$, Swales JD. Effects of treatment for hypertension on cerebral haemorrhage and infarction. Br Med F 1984;289:156-9.

26 Britton M, Hindmarsh T, Murray V, Tydén SA. Diagnostic errors discovered by CT in patients with suspected stroke. Neurology 1984:34:1504-7.

27 Central Bureau of Statistics. Population projection for Sweden 1983-2025. Stockholm: Liber, 1983.

\title{
Mortality probability in victims of fire trauma: revised equation to include inhalation injury
}

\author{
CHRISTOPHER J CLARK, WILLIAM H REID, WILLIAM H GILMOUR, \\ DONALD CAMPBELL
}

\begin{abstract}
There are no clear guidelines on the early diagnosis of injury due to inhalation of smoke. A clinical scoring system in the form of a previously prepared questionnaire may be used in the accident and emergency department by staff who are inexperienced in the management of inhalation injury. By quantifying injury due to smoke inhalation, its contribution to mortality in a large group of fire victims was established and a revised mortality probability equation derived using age, percentage surface area of the burn, and extent of inhalation injury.

This mortality probability equation may be used to divide patients into risk categories for early intensive care management and allows the comparison of mortality data between accident and emergency units receiving varying numbers of patients with injuries due to burns and smoke inhalation.
\end{abstract}

\section{Introduction}

The two most important advances in the management of patients suffering from burns - namely, early intravenous fluid resuscitation after the burn ${ }^{1}$ and the introduction of effective topical chemo-

\footnotetext{
University Department of Anaesthesia and Regional Burns Unit, Glasgow Royal Infirmary, Glasgow G31 2ER

CHRISTOPHER J CLARK, MD, MRCP, consultant physician, Hairmyres Hospital, East Kilbride, and honorary lecturer in medicine, University of Glasgow

WILLIAM H REID, MB, FRCS, consultant surgeon, also titular professor, University of Strathclyde

DONALD CAMPBELL, FFARCS, FRCP, professor of anaesthesia

Department of Statistics, University of Glasgow, Glasgow

WILLIAM H GILMOUR, MSC, FIS, lecturer in statistics
}

Correspondence and requests for reprints to: Dr Clark, University Department of Anaesthesia. therapy, particularly the sulphonamides in the $1960 \mathrm{~s}^{2}$-led to a revised analysis of mortality from burns by Bull in $1971 .^{3} \mathrm{He}$ produced a probability chart based on probit analysis for age of patient and percentage of the body surface area burnt, and this has been used widely as a standard reference in assessing the mortality figures from burns units. There has, however, been a gradual increase in the number of casualties from fires in recent years, and over half of the resulting deaths may be expected to occur as a direct result of inhalation of smoke. ' $T$ This is paralleled by an increasing use of synthetic polymers in household construction, furnishings, and decoration. ${ }^{\circ}$

In the regional burns unit at Glasgow Royal Infirmary mortality from burns has increased beyond that expected from Bull's mortality probability chart in parallel with an increase in the pulmonary complications in patients with concomitant injury due to smoke inhalation. We analysed the influence of smoke inhalation on mortality probability, quantified prospectively by a clinical data score plus estimation of carboxyhaemoglobin concentration, to see whether Bull's mortality probability chart underestimates the patients' risk of injury due to smoke inhalation in situations where fire trauma with concomitant smoke inhalation is common. The system of collecting clinical data was directed towards ease of use by the casualty officer without requiring previous experience of managing inhalation injury. The derived mortality probability equation was also intended to give an immediate estimate of risk using any simple calculator with a log function.

\section{Subjects and methods}

\section{SUBJECTS}

For a consecutive period of 18 months all casualties from house fires requiring assessment and treatment at Glasgow Royal Infirmary for suspected smoke inhalation, with or without surface burns, were included in the study. The initial criterion for inclusion was either the complaint by the patient or, when the patient was unable to give a coherent history, a report by the attending firemen and ambulance crew that the patient was at risk from possible smoke inhalation. 


\section{COLLECTION OF CLINICAL DATA}

The system of collecting clinical data, which has been reported previously, was based on the various clinical features accepted by authors such as Stone $e t a l,{ }^{8}$ Divincenti $e t a l,{ }^{9}$ and Brown ${ }^{10}$ as being indicative of injury due to smoke inhalation. In this study all of these clinical features were tabulated. The previously printed questionnaire had a format that was easy to use-that is, requiring answers to short questions on a yes/no basis-and could be completed quickly as there was direct liaison with the fire services, allowing communication with the leading fireman at the fire control headquarters as soon after the fire as possible.

For each patient a clinical score was collated and used to indicate the likelihood of smoke inhalation. A point was given for the presence of each clinical factor considered to be suggestive of smoke inhalation to a total of seven points as follows: (1) A history of being trapped in a house or industrial fire in an enclosed space. (2) Production of carbonaceous sputum. (3) Perioral facial burns - that is, affecting nose, lips, mouth, or throat. (4) Altered level of consciousness at any time after the incident and including confusion. (5) Symptoms of respiratory distress, such as a sense of suffocation, choking, breathlessness, and wheezing or discomfort affecting the eyes or throat, indicating irritation of the mucous membranes. (6) Signs of respiratory distress including stertorous, laboured breathing, and tachypnoea or auscultatory abnormalities, such as crepitations or rhonchi. (7) Hoarseness or loss of voice.

A score of greater than 2 was considered to fulfil the criteria for unequivocal smoke inhalation, and the aggregate score obtained for each patient was used as a probable indicator of the severity of injury due to smoke inhalation.

\section{ESTIMATION OF BLOOD CARBOXYHAEMOGLOBIN CONCENTRATION}

Carboxyhae.noglobin concentration (\%) was measured by an automated spectrophotometric method using an IL282 Co-oximeter. An estimation of the carboxyhaemoglobin concentration at exposure was then calculated by nomogram.

Arterial blood gas analysis and chest radiography were also performed routinely.

\section{STEPWISE LINEAR LOGISTIC REGRESSION ANALYSIS}

We used stepwise linear logistic regression analysis as described by Dixon and Brown ${ }^{11}$ to derive a suitable regression equation containing the

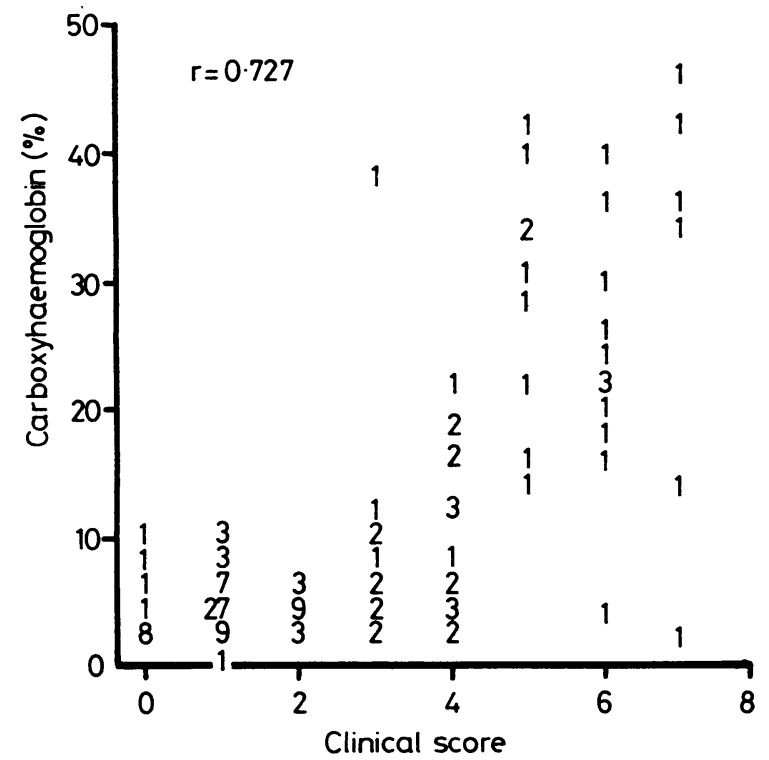

FIG $1-$ Clinical score against carboxyhaemoglobin concentration at exposure. Numbers represent individual patients.

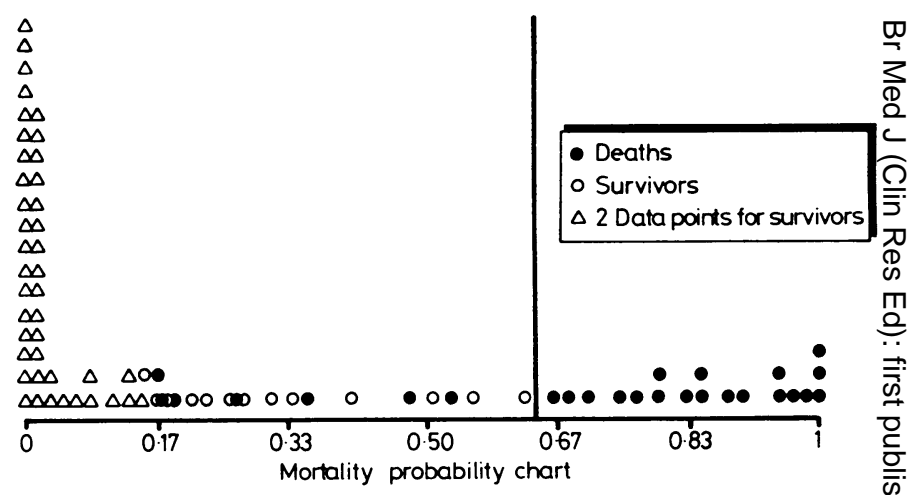

FIG 2-Summary of actual outcome in study group in relation to mortality probability classification.

variables recorded in this study to predict the probability of death as the outcome in the study group. The contribution of each individual variable to death was calculated, and the final equation incorporated those variablese shown significantly and independently to relate to death.

Data analysis was performed on an ICL2988 mainframe computer, using the BMDP statistical package, in the department of statistics, University oft Glasgow.

\section{Results}

A total of 128 patients entered the study (97 men, 31 women). Ages ranged from 4 to 85 (mean 27) years. Ninety two patients had surface burns, of whom 30 had no appreciable inhalation as judged by clinical assessment $-\vec{V}$ that is, a score of $<2$ and normal carboxyhaemoglobin concentration $(<10 \%)$-and the remaining 36 patients had smoke inhalation alone.

Figure 1 shows the high correlation between clinical score and carboxyhaemoglobin concentration at exposure as indicators of the extent of injury due to smoke inhalation. Three patients had a high score-that is, 6-7-bup low carboxyhaemoglobin concentrations. All had severe burns $(>60 \%)$ associated with oral burns and respiratory distress. This led to an in-o appropriately high score for the degree of smoke inhalation but highlightso the additional contribution of direct thermal trauma to inhalation injury to the upper airway and thus also to mortality. One other patient had a higho carboxyhaemoglobin concentration with a clinical score of only 3 owing to̊ inadequate collection of data because of severe alcohol intoxication. This weakness of the clinical score highlights the potential role for carboxy-3 haemoglobin concentration estimation when clinical data are lacking.

The table divides patients with surface burns into categories of mortality probability as defined by $\mathrm{Bull}^{3}$ and compares these with the actual. proportion of deaths in each category, expressed as a percentage of the totas in each burn category. In each category there is an increase in actuas mortality over predicted mortality, and the overall number of deaths for theo group with burns is 27 , compared with a predicted mortality of $18 \cdot 7$.

Stepwise linear logistic regression analysis used to compare fittedo equations for prediction of mortality using the variables age, percentage burns, symptom score, carboxyhaemoglobin concentration, and estimated carboxyhaemoglobin concentration at exposure showed that the besc equation for prediction of outcome comprised age, percentage burn, and symptom score as follows: $\mathrm{p}=\mathrm{e}^{\mathrm{z}} /\left(1+\mathrm{e}^{\mathrm{z}}\right)$, where $\mathrm{z}=-7 \cdot 9+0 \cdot 78 \times$ symptom score $+0.094 \times$ percentage burns $+0.034 \times$ age and $p=$ probability of death ono a scale from 0 to 1 . The equation was highly predictive when applied to the study group. For instance, at an arbitrary probability of $0 \cdot 66,121$ (94\%) oui of the 128 patients were correctly classified: $102(100 \%)$ who survived and $190 \mathrm{~W}$ (74\%) who died. Below a probability of $0 \cdot 17$ all patients survived (fig 2).

Fitted equations incorporating blood carboxyhaemoglobin concentrations on admission and at exposure provided no further predictive effect. Whenc clinical score was excluded, however, representing a theoretical case ine which clinical information was lacking, the next best equation for prediction of mortality used age, percentage burns, and carboxyhaemoglobin concentration at exposure as follows: $z=-9 \cdot 7+0.086 \times$ carboxyhaemoglobin con $\frac{\mathbb{\Phi}}{0}$ centration at exposure $+0 \cdot 18 \times$ percentage burns $+0.061 \times$ age.

Substitution of carboxyhaemoglobin concentration on admission for that

Patients with burns grouped according to Bull's probability of death categories ${ }^{3}$ compared with proportion of deaths found in the study

\begin{tabular}{|c|c|c|c|c|c|c|c|c|c|c|c|}
\hline $\begin{array}{l}\text { Mortality probability (\%): } \\
\text { Proportion of deaths (\%): }\end{array}$ & $\begin{array}{c}0 \\
2 / 67(3)\end{array}$ & $\begin{array}{c}10 \\
0 / 21(0)\end{array}$ & $\stackrel{20}{5 / 11(45)}$ & $\begin{array}{c}30 \\
5 / 7(71)\end{array}$ & $\begin{array}{c}40 \\
0 / 1(0)\end{array}$ & $\begin{array}{c}50 \\
1 / 2(50)\end{array}$ & $\begin{array}{c}60 \\
1 / 2(50)\end{array}$ & $\begin{array}{c}70 \\
1 / 1(100)\end{array}$ & $3 / 3(100)$ & $\begin{array}{c}90 \\
6 / 6(100)\end{array}$ & $\begin{array}{l}100 \\
3 / 3(100)\end{array}$ \\
\hline
\end{tabular}


at exposure-that is, corrected-reduced the predictive effect of the equation, though carboxyhaemoglobin concentration on admission was shown to have an additional independent relation with mortality once age and percentage burns were taken into account. Arterial blood gas analysis and abnormalities seen on chest radiography showed no additional relation with mortality.

\section{Discussion}

Bull's mortality probability chart is an important prognostic index for comparison of mortalities in burnt patients. ${ }^{3}$ It does not, however, take injury due to smoke inhalation into account.

This study confirms the apparent discrepancy between our actual and predicted mortality figures based on Bull's chart, which will probably reflect the additional hazard of injury due to smoke inhalation. Stepwise linear logistic regression analysis has been used to identify independent prediction of outcome in other clinical contexts, such as analysis of the risk of death after a portacaval shunt operation, ${ }^{12}$ and was highly accurate in predicting mortality in this study. The new equation has the further benefit of allowing mortality probability to be calculated for various victims of fire trauma, including patients with burns alone, those with a combination of smoke and burn injuries, and those suffering from smoke inhalation alone. The mortality probability chart could be used to differentiate patients into general categories such as low, medium, and high risk patients to plan management-for example, elective transfer to intensive care facilities soon after admission. Patients with calculated mortality probabilities of $0-0.33,0.33-0.66$, and $\geqslant 0.66$ would be low, medium, and high risk patients, respectively. All high risk patients should be transferred directly from the accident and emergency department to the respiratory intensive care unit for management.

This study shows that the extent of smoke inhalation may be quantified by either clinical score or carboxyhaemoglobin concentration at exposure. We emphasise that the accuracy of the clinical score depends on the kind of careful collection of data used in this study. From previous experience we conclude that medical staff at all levels find considerable difficulty in managing inhalation injury owing to uncertainties about relevant clinical findings, arterial blood gas analysis, chest radiography, and the role of blood carboxyhaemoglobin concentration measurement. This is exacerbated by the lack of formal undergraduate and postgraduate teaching on the subject. ${ }^{14}$ We therefore suggest incorporating the clinical score plus carboxyhaemoglobin concentration at exposure into the routine surveillance of fire victims attending the accident and emergency unit for assessment.

Finally, the mortality probability equation may be derived with a simple calculator with a $\log$ function and should be applied prospectively to data on the patient from other units before validation of their accuracy and discriminative role in identifying the risk of death in victims of fire trauma.

We thank the Scottish Home and Health Department and the Fire Service Research and Training Trust for their support with this project.

\section{References}

1 Black DAK. Treatment of burn shock with plasma and serum. BrMed $\mathcal{F}$ 1940;ii:693-7. 2 Jackson DM. Burns: McIndoe's contribution and subsequent advances. Ann $R$ Coll Surg Engl 1979;61:335-40.

3 Bull JP. Revised analysis of mortality due to burns. Lancet 1971;ii: 1133.

4 Vivori E, Cudmore RE. Management of airway complications of burns in children. $\mathrm{Br}$ Med $\mathcal{F}$ 1977;ii:1462-4.

5 United Kingdom Fire Statistics (1976). London: HMSO, 1978.

6 Anonymous. Two-part survey of the British plastics industry. British Plastics 1970-1;44:59-80.

7 Clark CJ, Campbell D, Reid WH. Blood carboxyhaemoglobin and cyanide levels in fire survivors. Lancet 1981;i:1332.

8 Stone HH, Rhame DW, Corbitt JD, Given KS, Martin JD. Respiratory burns: a correlation of clinical and laboratory results. Ann Surg 1976;165:157-68.

9 Divincenti FC, Pruitt BA, Reckler JM. Inhalation injuries. F Trauma 1971;11:109-17

10 Brown JM. Inhalation injury and progressive pulmonary insufficiency in a British burns unit. Burns 1977;4:32-43.

11 Dixon WJ, Brown MB. BMDP 1981 manual. Berkeley, California: University of California Press, 1982.

12 Ryan TA, Joiner BL, Ryan BF. Minitab: student handbook. North Scituate, Massachussetts: Duxbury Press, 1976

13 Grendell JH, Cello JP, Margaretten W, Heilbron DC. Impact of preshunt liver histology on survival following porta-systemic shunt surgery for bleeding esophageal varices. Dig Dis $\mathrm{Sci}$ 1983;128:44-55.

14 Matthews R. Burning question over doctor training lapses. Hospital Doctor 1986;C6:4, 13.

(Accepted 2 April 1986)

\section{Screening for scoliosis: the problem of arm length}

The forward bend test is an integral part of the assessment of scoliosis, whether for screening purposes or in the established condition. The introduction of the scoliometer, an inclinometer placed over the area of maximal deformity, has provided a rapid method of quantifying the rib or lumbar hump, and a recommended threshold for further follow up or orthopaedic assessment has been suggested. ${ }^{1}$ An increased prevalence of arm length asymmetry exists in adolescent idiopathic scoliosis. ${ }^{2}$ The influence of this recognised variable on forward bend assessment has been ignored in many papers reporting results from scoliosis screening programmes. Some reports recommend that the arms hang freely (position A), ${ }^{3}$ others that the hands are placed together with fingertips apposed (position B), ${ }^{45}$ and in many no accurate description of the position used is given. We examined the effect of different arm positions on scoliometer readings in 113 schoolchildren.

\section{Patients, methods, and results}

One hundred and thirteen schoolchildren (41 girls and 72 boys) aged 13 or 14 were examined by two independent observers. Arm lengths (from acromion to tip of middle finger) were measured to the nearest $\mathrm{mm}$. Scoliometer readings of the magnitude and direction of any asymmetry were taken at the level of the spinous processes of the fourth and eighth thoracic vertebrae in positions $A$ and $B$ (described above) and also with the fingertips of the left hand apposed to the proximal finger crease of the right hand (position $\mathrm{C}$ ) and vice versa (position $\mathrm{D}$ ).
Both observers showed the right arm to be longer than the left in the group overall and in girls. In boys, however, the right arm was longer when recorded by one observer and the left when recorded by the other (see table). The maximum difference observed in arm length was $24 \mathrm{~mm}$.

Mean (SEM) scoliometer readings (in scoliometer degrees). Positive values indicate a left sided rib hump, negative values a right sided rib hump

\begin{tabular}{|c|c|c|c|}
\hline Position & $\begin{array}{l}\text { Thoracic } \\
\text { vertebrae }\end{array}$ & Girls & Boys \\
\hline A & $\left\{\begin{array}{l}\mathrm{T} 4 \\
\mathrm{~T} 8\end{array}\right.$ & $\begin{array}{r}-0.27(0.27) \\
0.00(0.32)\end{array}$ & $\begin{array}{l}-0.42(0.16) \\
-0.06(0.18)\end{array}$ \\
\hline B & $\left\{\begin{array}{l}\mathrm{T} 4 \\
\mathrm{~T} 8\end{array}\right.$ & $\begin{array}{l}-0.28(0.26) \\
-0.17(0.34)\end{array}$ & $\begin{array}{r}-0.45(0.17) \\
0.02(0.17)\end{array}$ \\
\hline $\mathrm{C}$ & $\left\{\begin{array}{l}\mathrm{T} 4 \\
\mathrm{~T} 8\end{array}\right.$ & $\begin{array}{l}-5.60(0.28) \\
-3.06(0.31)\end{array}$ & $\begin{array}{l}-6 \cdot 10(0.25) \\
-2.99(0.22)\end{array}$ \\
\hline $\mathrm{D}$ & $\left\{\begin{array}{l}\mathrm{T} 4 \\
\mathrm{~T} 8\end{array}\right.$ & $\begin{array}{l}5.28(0.30) \\
2.88(0.33)\end{array}$ & $\begin{array}{l}5.40(0.23) \\
3.08(0.20)\end{array}$ \\
\hline
\end{tabular}

There was a highly significant correlation in the scoliometer readings recorded by the two observers in all positions $(p<0.0001)$, and thus mean scoliometer readings were subsequently used. The table gives the mean scoliometer reading in each position. A significant correlation (Pearson product-moment) between the difference in arm length and the change in scoliometer reading between position $A$ and B was found only by one observer, at T8 $(p<0.02)$. Positive correlations were found, however, between these two variables for both observers for the whole group and for the girls alone; all but one of the coefficients for the boys were 